\title{
DESIGN OF ANTENNAS FOR HYBRID FSO/RF TRANSMISSION SYSTEM
}

\author{
Maroš LAPČÁK, L’uboš OVSENÍK, Jakub ORAVEC, Norbert ZDRAVECKÝ \\ Department of Electronics and Multimedia Communications, Faculty of Electrical Engineering and Informatics, \\ Technical University of Košice, Letná 9, 04200 Košice, Slovak Republic, \\ Tel. +421 55602 4277, E-mail: maros.lapcak@tuke.sk
}

\begin{abstract}
The purpose of this publication is to create and correctly analyse a secondary RF line for a hybrid FSO/RF system. Since we want to ensure almost $100 \%$ functionality, the design of a secondary RF line is very important. In our case, we have chosen two types of antennas. First, it was a helical antenna that achieves a high level of efficiency and much smaller dimensions compared to horn antennas. The second type was just a horn antenna. Its advantages are high efficiency, high gain, and narrow width of radiation angle. However, large disadvantages are dimensions and the price of these antennas. However, in both cases, we can say that these antennas are suitable for deployment to our hybrid FSO/RF system.
\end{abstract}

Keywords: antenna efficiency, Free Space Optics, helical antenna, horn antenna, hybrid FSO/RF, radio frequency, VSWR

\section{INTRODUCTION}

FSO (Free Space Optics), shown in Fig. 1, is a technology that uses modulated optical beams to provide wireless data transmission. Communication in this system can take place over short, medium, but also long distances. This means that use is possible for a few meters, but also for up to $7 \mathrm{~km}$. A laser is used to create the optical beam, which means that it is necessary to have line-of-sight between the devices communicating in these ways. This laser is housed in heads that can operate in full duplex mode. FSO systems work with wavelength bands from $780-1600 \mathrm{~nm}$. This means that there is no need to lease licensed frequency bands and it is also not necessary to operate an optical beam for electrical pulses as in the case of RF systems. The biggest advantages are the large bandwidth and high data rate compared to a conventional RF system. Other advantages include ease of installation and commercial availability. Due to these advantages, these systems are used for various applications, such as aeronautical and satellite communications, temporary but also permanent connections between buildings [1] - [6].

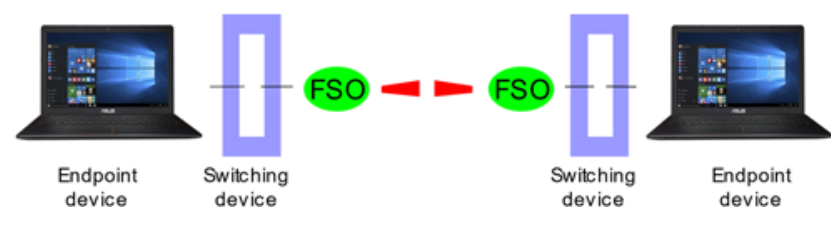

Fig. 1 Example of FSO communication

The hybrid FSO/RF system consists of two systems, as shown in Fig. 2. One is the FSO system as shown in the picture, and the other is the radio frequency (RF) system. For hybrid systems like this, we distinguish between primary and secondary systems. The primary system in this case is the FSO system, as it provides much higher transmission speeds compared to conventional RF systems. For this reason, the RF system is a secondary system that provides redundancy of the FSO system in the event of adverse conditions for the primary system. Precisely because of redundancy, these networks use systems with different methods of information transmission. This combination was chosen deliberately, as the biggest problem with the FSO system is fog, and this atmospheric phenomenon does not have a major impact on the operation of RF systems [7] - [9].

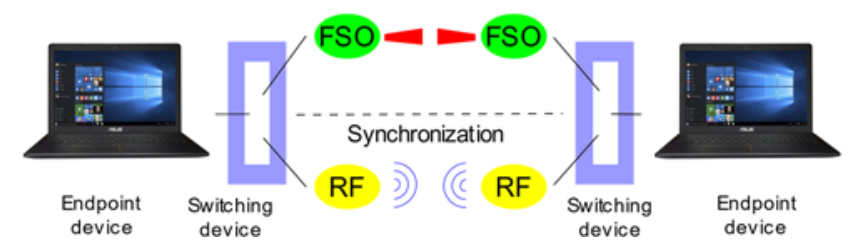

Fig. 2 Principle of operation of a hybrid FSO/RF system

This research is devoted to the design of a secondary RF line for a hybrid FSO/RF system. If we want to eliminate all the adverse effects on this system, we must also choose the right type of RF line in our case. We decided on another unlicensed $5.8 \mathrm{GHz}$ band. In part 3 , the designs of two antennas will be described and analysed in more detail, and in part 4 we will get acquainted with the results of simulations and analysis of individual antennas.

\section{DESIGN OF SECONDARY RF LINES FOR HYBRID FSO/RF SYSTEM}

Radio frequency technologies do not have an easy task, as they must provide a reliable secondary communication line for a hybrid FSO/RF system. Indoors, RF signals encounter physical obstacles. These obstacles in turn cause reflection, diffraction, and shading. In the exteriors, the most influencing factor is rain. It is an uncontrollable variable that results in attenuation, interruption, or unreliability of the communication line. $100 \%$ connection availability is expected. However, it is unrealistic, especially when used outdoors, mainly because it is not possible to create an accurate weather forecast. In heavy rain, the range of the $\mathrm{RF}$ connection decreases due to attenuation. Under normal circumstances, a communication link can achieve a bit error rate of $10^{-6}$ or better. The system should be able to provide $99.99 \%$ availability [10] [11]. 


\subsection{Helical antenna}

Helical antennas fall into the category of reflector antennas because they are based on two parts. The first part is a conductor forming the active part of the antenna, which can be wound in two directions, which determines the type of polarization of the radiating characteristic of the antenna. If the wire forming the helix of the antenna is wound in the direction of the left-hand screw, then the resulting polarization will be of the left-hand circular polarization type and is referred to as LHCP (Left Hand Circular Polarization). If the wire forming the helix of the antenna is wound in a clockwise direction, we speak of right-hand circular polarization and call it RHCP (Right Hand Circular Polarization). The second part of the helical antenna is the reflector, which allows you to effectively direct the radiation of the antenna. The helical antenna is characterized by the ability to work in various modes. The operating modes are axis mode, normal mode, and conical radiation mode. In the axial radiation mode, the main radiation lobe is oriented in a direction along the helix and is characterized by a low level of lateral lobes. This mode can be achieved if the circumference of the helix is adjusted in relation to the free length. If the diameter of the helix is much smaller than the wavelength, the radiation is identical to that of the dipole antenna, i.e., the radiation is perpendicular to the axis of the helix [12] - [15].

This helical antenna consists of two helices, which means that it is a bifilar helical antenna. The length of the spirals and their diameter were adjusted for a higher operating frequency as well as the number of turns. The conductor thickness was chosen to be $1.2 \mathrm{~mm}$. FR-04 material was used for the core of the printed circuit board. All antenna parameters are listed in Table 1.

Table 1 Parameters of our proposed helical antenna with an operating frequency of $5.8 \mathrm{GHz}$

\section{Parameters}

\begin{tabular}{lc}
\hline Antenna type & Helical antenna \\
\hline Work frequency & $5.8 \mathrm{GHz}$ \\
\hline Spiral length & $85 \mathrm{~mm}$ \\
\hline Spiral diameter & $18 \mathrm{~mm}$
\end{tabular}

Number of threads

7

\begin{tabular}{lc}
\hline Direction of threads & Right-handed threads \\
\hline PCB dimensions & $\begin{array}{c}71 \times 1 \mathrm{~mm} \\
\text { (diameter } \times \text { thickness) }\end{array}$ \\
\hline $\begin{array}{l}\text { Dimensions of the grounding } \\
\text { area }\end{array}$ & $\begin{array}{c}71 \times 0.035 \mathrm{~mm} \\
\text { (diameter } \times \text { thickness) }\end{array}$
\end{tabular}

Used Wire

Power type
Copper, FR-04

SMA Connector for

Coaxial Driver

Connection
Based on Fig. 3, where the VSWR (Voltage Standing Wave Ratio) values are shown, we can see the wide band of this helical antenna. The VSWR value is below 2 in the frequency range of $4.34 \mathrm{GHz}$ to $6.67 \mathrm{GHz}$. The minimum is at $5.8 \mathrm{GHz}$ and the VSWR is at 1.01 , indicating an almost ideal impedance matching. We can convert VSWR values to the level of reflected power from the antenna. In this case, if we want to convert the VSWR value achieved at $5.8 \mathrm{GHz}$, then the reflected power will reach $-48 \mathrm{dBi}$. For comparison, in the case of the $6.2 \mathrm{GHz}$ frequency, when the VSWR value is 1.75 , the reflected power is $-11.3 \mathrm{dBi}$.

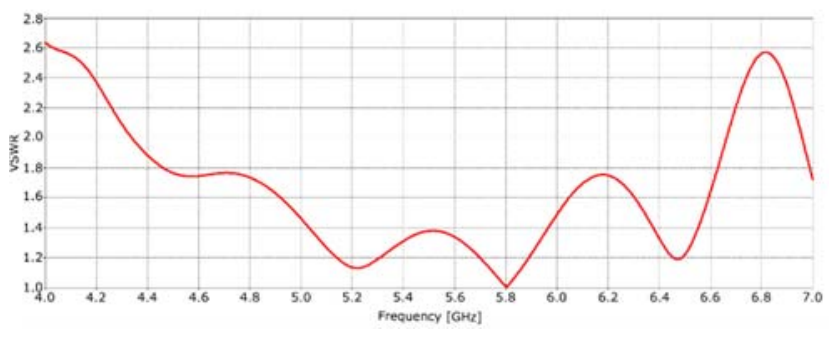

Fig. 3 VSWR values of a helical antenna with a working frequency of $5.8 \mathrm{GHz}$ in the CST studio package shown in a linear graph

The efficiency of this antenna is shown in Fig. 4. At an operating frequency of $5.8 \mathrm{GHz}$, the antenna achieves more than $99 \%$ efficiency. During the entire width of the unlicensed frequency band, the antenna achieves an efficiency of more than $97 \%$. This antenna can be considered as broadband, as in the whole band, where the VSWR value is below 2, the antenna achieves more than $88 \%$ efficiency.

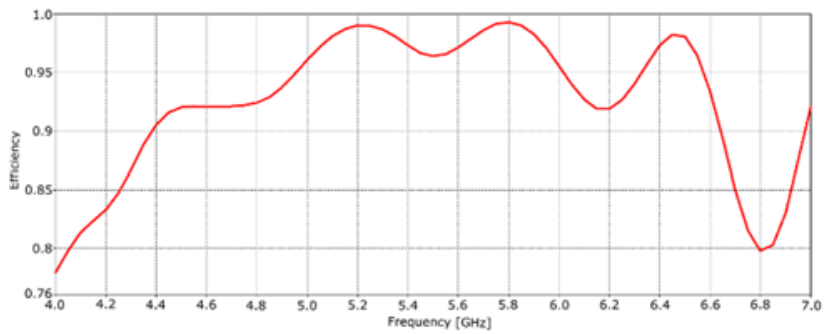

Fig. 4 Efficiency of a helical antenna with a working frequency of $5.8 \mathrm{GHz}$ in the CST studio package

The radiating characteristic of this antenna is shown in Fig. 5 a), b). As in the previous cases, the radiation characteristic is represented by sections at angles $\phi=0^{\circ}$ and $\phi=90^{\circ}$. The section angle $\phi=0^{\circ}$ is located on the top of the figure. Again, it is possible to see the direction of the maximum gain, shown by the dark blue line, and the width of the beam angle, which is shown in light blue. The maximum gain of this antenna reaches the level of $13.7 \mathrm{dBi}$, while the width of the beam angle is $35^{\circ}$. On the bottom side of the figure, where the radiation characteristic is shown at a section angle $\phi=90^{\circ}$, we can see the same level of maximum gain and almost the same width of the radiation angle, which is at the level of $34.9^{\circ}$. 

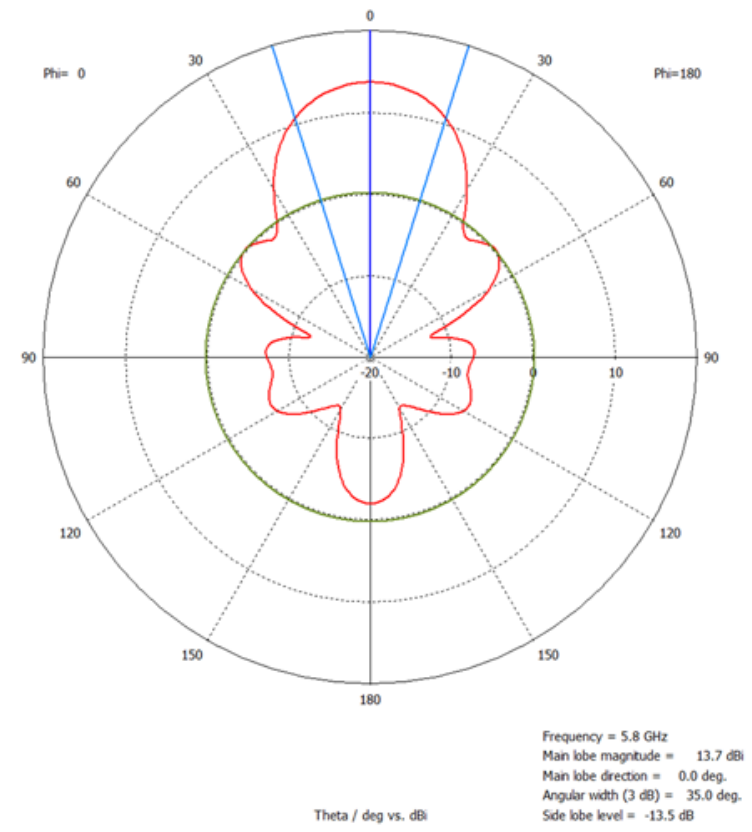

a)

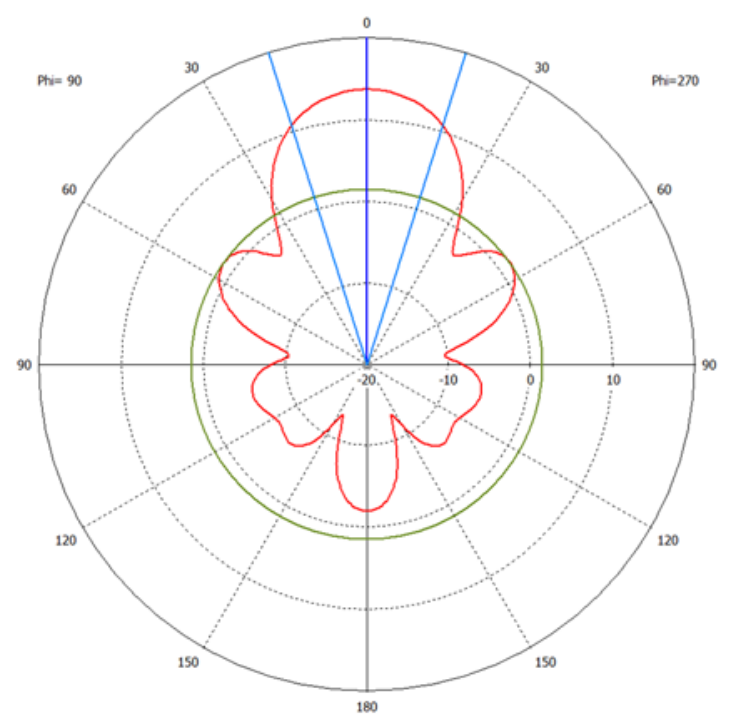

Frequency $=5.8 \mathrm{GHz}$
Man ibe magntude $=13.7 \mathrm{~dB}$

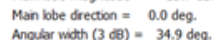
Theta / deg vs. dBi Anguar woth $(3 \mathrm{~dB})=34.9 \mathrm{deg}$
side bebe level $=-12.2 \mathrm{~dB}$

b)

Fig. 5 a), b) Radiation characteristics of a helical antenna with a working frequency of $5.8 \mathrm{GHz}$ in the CST studio package in a polar graph at sections with angles $\phi=0^{\circ}$ and $\phi=90^{\circ}$

\subsection{Horn antenna}

Horn antennas are characterized by high gain (more than $15 \mathrm{dBi}$ ), acceptable level of side lobes, low power consumption and relatively low price.

In this horn antenna design, a monopole antenna is used as the radiator and the horn antenna body serves as the ground surface of the radiator. This antenna is also made of aluminium with a thickness of $1 \mathrm{~mm}$ and the radiator is formed by a conductor with a radius of $1 \mathrm{~mm}$. All antenna parameters are shown in Table 2.
Table 2 Parameters of a horn antenna with an operating frequency of $5.8 \mathrm{GHz}$

Parameters

Description

\begin{tabular}{lr}
\hline Antenna type & Horn antenna \\
\hline Work frequency & $5.8 \mathrm{GHz}$ \\
\hline Dimensions of waveguide & $\begin{array}{c}4.9 \times 2.3 \times 2.3 \mathrm{~cm} \\
\text { (width x height } \mathrm{x} \text { length) }\end{array}$ \\
\hline Dimensions of horn & $\begin{array}{c}20.4 \times 25.5 \times 16.7 \mathrm{~cm} \\
\text { (width x height } \times 1 \text { length) }\end{array}$ \\
\hline Power type & $\begin{array}{c}\text { Copper, FR-04 } \\
\text { Coaxial Driver } \\
\text { Connection }\end{array}$ \\
\hline
\end{tabular}

Fig. 6 Section of a horn antenna with a working frequency of $5.8 \mathrm{GHz}$ in 3D display in the FEKO package

In Fig. 6 the sides parallel to the $\mathrm{X}$-axis have several openings, while also containing ribs. The sides parallel to the $\mathrm{Y}$ axis are solid without holes and ribs. As with the horn antenna with the operating frequency, the height of these holes is now sufficient to describe the holes. The height of individual holes is described in Table 3 . The holes are rearranged from bottom to top.

Table 3 The heights of the holes in the horn antenna with a working frequency of $5.8 \mathrm{GHz}$ on the sides parallel to the $\mathrm{X}$ axis

\begin{tabular}{ll} 
Holes & Height \\
\hline First hole & $0.8 \mathrm{~cm}$ \\
\hline Second hole & $5.2 \mathrm{~cm}$ \\
\hline Third hole & $6.8 \mathrm{~cm}$ \\
\hline Fourth hole & $1 \mathrm{~cm}$ \\
\hline Fifth hole & $0.8 \mathrm{~cm}$
\end{tabular}


In Fig. 7 shows VSWR values based on the large bandwidth in which the antenna can radiate, as the VSWR values are below in the frequency range of $4.845 \mathrm{GHz}$ to $6.064 \mathrm{GHz}$. Although the minimum is not at the $5.8 \mathrm{GHz}$ operating frequency, the VSWR at this frequency is below 1.3. The minimum could be shifted to the operating frequency by further adjustments, but this is not necessary as it would not have a significant effect on the efficiency of the antenna and could negatively affect the radiation characteristics of the antenna.

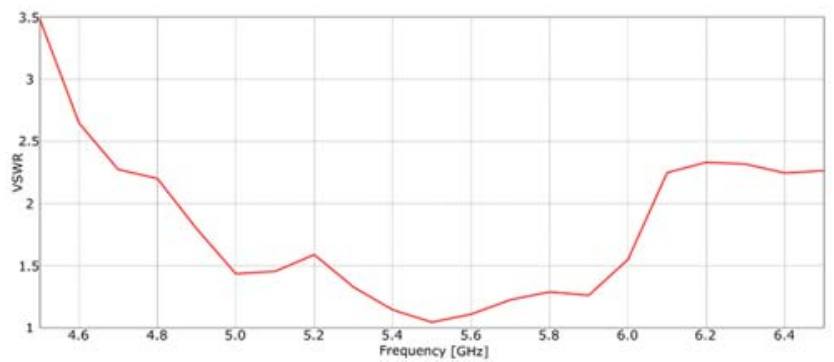

Fig. 7 VSWR values of a horn antenna with an operating frequency of $5.8 \mathrm{GHz}$ in the FEKO package shown in a linear graph

Referring to Fig. 8 we can see that the efficiency of this horn antenna is very high, because at maximum the antenna reaches an efficiency of more than $99 \%$ and is located at a frequency of $5.5 \mathrm{GHz}$. Furthermore, we can see that the statement about high bandwidth is true, as the efficiency in this frequency range is more than $85 \%$. It can also be seen from the figure that the efficiency of this antenna in the unlicensed frequency band in which the antenna will operate decreases the efficiency of the antenna. However, the efficiency in this band does not fall below $95 \%$.

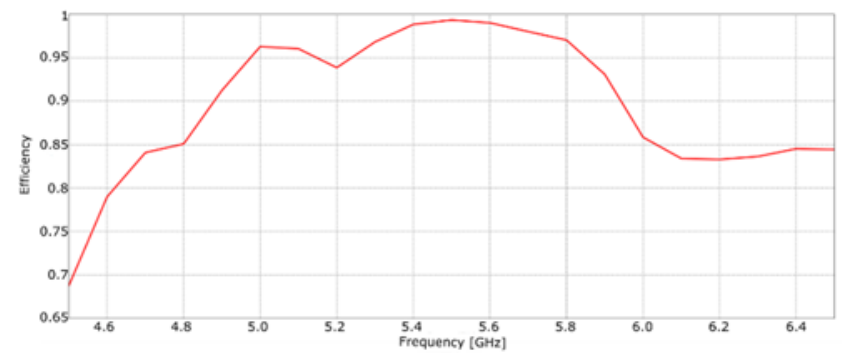

Fig. 8 Efficiency of a horn antenna with an operating frequency of $5.8 \mathrm{GHz}$ in the FEKO package

As in the previous cases, the radiation characteristic is now shown in Fig. 9 for sections with angles $\phi=0^{\circ}$ and $\phi=90^{\circ}$. On the top of the figure, where the section of the radiation characteristic at an angle $\phi=0^{\circ}$ is shown in red, the maximum level of obtained gain is $17.93 \mathrm{dBi}$ and the radiation angle is at $16.08^{\circ}$. The bottom side shows the section of the radiation characteristic at an angle $\phi=90^{\circ}$, the antenna reaches a maximum gain of $17.693 \mathrm{dBi}$ and the radiation angle is at the level of $21.8^{\circ}$. The maximum gain for both sections is the same, so the direction of maximum radiation is not shifted. It is also possible to see the formation of side lobes, but these side lobes have a low gain compared to the maximum gain. To compare directionality and gain, the maximum directionality value is $17.755 \mathrm{dBi}$. This is a difference of only $0.062 \mathrm{dBi}$ compared to the maximum gain, which means that if the efficiency is above
$90 \%$, it is not necessary to state the directionality and the gain of the antenna, as the differences in these two parameters are minimal. Also with a section angle $\phi=90^{\circ}$ it is possible to notice a slight deformation of the radiation characteristic, but since the direction of radiation with maximum gain is the same for both sections, this deformation is not a significant problem.

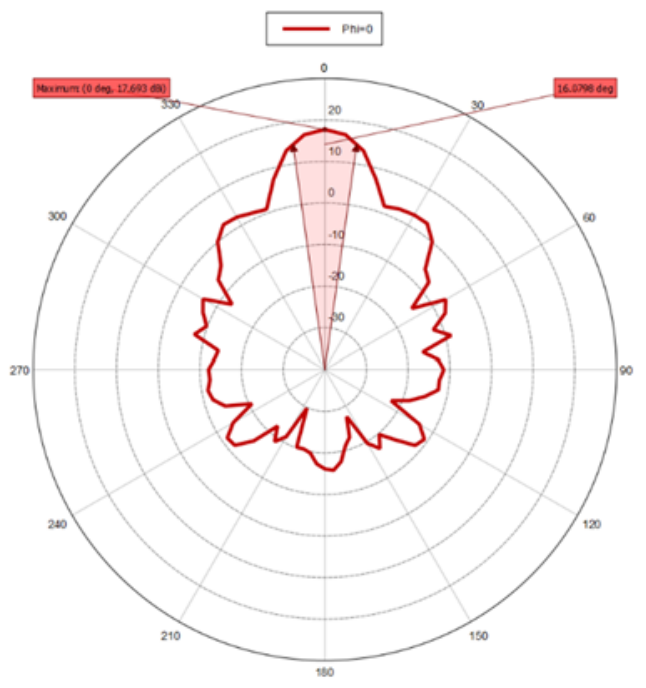

a)

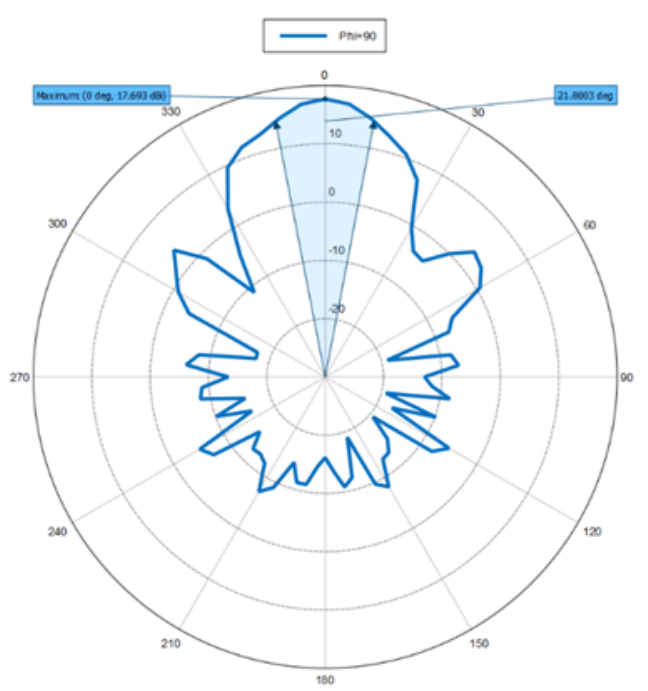

b)

Fig. 9 a) b) Radiation characteristics of a horn antenna with an operating frequency of $5.8 \mathrm{GHz}$ in the FEKO package in a polar graph at sections with angles $\phi=0^{\circ}$ and $\phi=90^{\circ}$

\section{RESULTS}

From the results of the simulations, it is possible to see the excellent impedance matching of this antenna and at the same time its high efficiency. The radiation characteristic sections show a high gain and a relatively narrow radiation angle. Based on this beam angle, we classify this antenna as a sector antenna. The main advantage of this antenna is its dimensions.

From the simulation results it is possible to see a very good impedance matching and a high level of efficiency of this horn antenna with a working frequency of $5.8 \mathrm{GHz}$. Impedance matching as well as efficiency also show the 
wide band in which the antenna can radiate. Although the antenna is simulated suitable for use, it is still very large compared to a helical antenna.

\section{CONCLUSIONS}

This paper focuses mainly on the simulation of antennas as a backup source for a hybrid FSO / RF system. Since we want to ensure almost $100 \%$ transmission $(99.99 \%)$, it is necessary to properly design a backup RF line. In our case, we chose two antennas, which differ from each other in many cases. Above all, it is the size of the individual antennas. The simulation results are described below.

Two antennas' models were created in this research. One is a horn antenna with a $5.8 \mathrm{GHz}$ working frequency. Its advantages are high level efficiency, high profit level and narrow width of radiation angle. All these benefits are required for hybrid FSO/RF system. However, this type of antenna has large disadvantages and the dimensions and the price of these antennas.

Another type of antenna was a helical antenna as well as a $5.8 \mathrm{GHz}$ working frequency. This type of antenna has achieved a high efficiency level and much smaller dimensions compared to the horn antenna. However, simulations show deterioration of gain and increase the width of the radiation angle. The biggest disadvantage of these antennas is high sensitivity to production error in their manufacturing process. Even the minimum movement of the spiral may cause deterioration of radiating characteristics.

As the simulations show, these antennas can also be used in real design, as they meet all the necessary parameters for proper operation. Both antennas are suitably impedance matched, as their radiation efficiency is more than $95 \%$ at our chosen frequency of $5.8 \mathrm{GHz}$. The gain of both antennas corresponds to the overall design and is evaluated very positively. Therefore, these antennas are suitable for the actual implementation and production.

\section{ACKNOWLEDGMENTS}

This work was supported by research projects VEGA $1 / 0584 / 20$ "UWB sensor systems for monitoring people working in real conditions (ReConLoc)" and FEI-2021-71 "Methods of data security in modern communication systems".

\section{REFERENCES}

[1] MALIK, A. - SINGH, P.: "Free Space Optics: Current Applications and Future Challenges," International Journal of Optics, 2015, Vol. 2015, No. 6, pp. $1-7$, DOI: 10.1155/2015/945483.

[2] TÓTH, J. - OVSENÍK, L. et. al.: “Classification prediction analysis of RSSI parameter in hard switching process for FSORF systems," Measurement, 2018, Vol. 116, pp. $602-610$, ISSN: 0263-2241.

[3] WELLS, J.: 'Faster than fiber: The future of milti-G/s wireless," IEEE Microwave Magazine, 2009, Vol. 10, No. 3, pp. 104 - 112, DOI: 10.1109/MMM.2009.932081 .
[4] ARNON, S. - BARRY, J. et. al.: "Advanced Optical Wire-less Communication Systems," GB: Cambridge Uni-versity Press, 2012, 404 p., ISBN: 0521197872.

[5] WILlEBRAND, H. - GHUMAN, B.: "Free Space Optics: Enabling Optical Connectivity in Today's networks (Sams Other)," USA - Indianapolis: Pearson Tech-nology Group, 2001, 288 p., ISBN: 978-0672322488.

[6] VIGNESHWARAN, S. - MUTHUMANI, I. et. al.: "Investiga-tions on Free space optics communication system," 2013 International Conference on Information Com-munication and Embedded Systems (ICICES), 2013, pp. 819 - 824, DOI: 10.1109/ICICES.2013.6508300.

[7] HALUŠKA, R. - OVSENÍK, L'. et.al.: "Prediction of Received Optical Power for Switching Hybrid FSORF System," Multidisciplinary Digital Publishing Institute, 2020, Vol. 9, No. 8, pp. 1 - 14, DOI: 10.3390/electronics9081261.

[8] HALUŠKA, R. - OVSENÍK, L.: "Example of Switching Hybrid FSORF Systems," Acta Electrotechnica et Informatica, 2020, Vol. 20, No. 4, pp. 27 - 31, DOI: 10.15546/aeei-2020-0022.

[9] STOTTS, L. B. - ANDREWS, L. C. et. al.: "Hybrid Optical RF Airborne Communications," Priceedings of the IEEE, 2009, Vol. 97, No. 6, pp. 1109 - 1127, DOI: 10.1109/JPROC.2009.2014969.

[10] MÁRTON, M. - OVSENÍK, L. et. al.: "Design of Helix Antenna for $9.2 \mathrm{GHz}$ in FEKO for FSORF Hybrid System Focused on Height of Helix," Carpathian Journal of Electronic and Computer Engineering, 2018, Vol. 11, No. 2, pp. 3 - 7, ISSN: 1844-9689.

[11] KORAI, U. A. - LUINI, L. - NEBULONI, R.: "Model for the Prediction of Rain Attenuation Affecting Free Space Optical Links," Electronics, 2018, Vol. 7, No. 12, 14 p., DOI: 0.3390 /electronics 7120407 .

[12] MÁRTON, M. - OVSENÍK, L. et. al.: "Návrh špirálovej antény pre $2,4 \mathrm{GHz}$ za účelom zvýšenia dostupnosti FSORF hybridného systému," Electrical Engineering and Informatics, 2018, Vol. 9, pp. 147 150, ISBN: 978-80-553-2713-6.

[13] MÁRTON, M. - OVSENÍK, L'. et. al.: "Design of helix antenna for $2.4 \mathrm{GHz}$ applicable in FSORF hybrid system," Proceedings of Mipro 2018, Opatija (Croatia), 2018, pp. 469 - 472, ISBN: 978-953-233096-0.

[14] MÁRTON, M. - OVSENÍK, L. et. al.: "Analysis of Helix Turns Impact on Design of Helix Antenna Operated on $2.46 \mathrm{GHz}$ Proposed for FSORF Hybrid System," Proceedings of Mipro 2019, Opatija (Croatia), 2019, pp. 537 - 540, ISBN: 978-953-233098-4.

[14] MÁRTON, M. - OVSENÍK, L. et. al.: "Porovnanie špirálových antén pracujúcich na $2,4 \mathrm{GHz} 5,2 \mathrm{GHz}$ a 
9,2GHz pre experimentálny FSO/RF systém," Electrical Engineering and Informatics 10: proceedings of the Faculty of Electrical Engineering and Informatics of the Technical University of Košice, Slovakia, 2019, pp. 162 - 164, ISBN: 978-80553-3342-7.

Received July 2, 2021, accepted September 17, 2021

\section{BIOGRAPHIES}

Maroš Lapčák received his M.Sc. degree from Faculty of Electrical Engineering and Informatics, Technical University of Košice in 2020 and now he continues as PhD student. His research interests include the study of data transmission limitations in FSO systems, the design of a hybrid FSO/RF system, the design of a backup RF line, hard and soft switching methods, and the recording of weather conditions in the atmosphere.
Norbert Zdravecký received his M.Sc. degree from Faculty of Electrical Engineering and Informatics, Technical University of Košice in 2020 and now he continues as $\mathrm{PhD}$ student. His research interests include data transmission limitation in all optical networks, optic communication systems.

Luboš Ovseník received his M.Sc. and PhD. degrees from Faculty of Electrical Engineering and Informatics, Technical University of Košice in 1990 and 2002, respectively. He works at the Technical University of Košice, now as an Associate Professor. His research interests include photonics, fiber optic communication systems and sensor networks.

Jakub Oravec received his M.Sc. and $\mathrm{PhD}$. degrees from Faculty of Electrical Engineering and Informatics, Technical University of Košice in 2015 and 2019, respectively. Nowadays, he serves as an Assistant Professor, his research interests include image encryption algorithms, steganography, and digital image processing. 